\title{
Comunicação, arte e educação em John Dewey ${ }^{1}$
}

\section{Resumo}

$\mathrm{O}$ artigo pretende analisar a articulação entre os conceitos de arte e comunicação propostos pelo educador norte-americano John Dewey (1856-1952), especialmente nas obras Democracia e Educação (1916) e A Arte como Experiência (1934), bem como inferir os desdobramentos desse raciocínio para a educação. Segundo o autor, a comunicação seria semelhante à arte, uma vez que os participantes, em ambos os processos, precisam desenvolver a empatia, levando em consideração a existência de um "outro" e se imaginando no lugar dele. Como para o autor a comunicação e a educação estão intimamente associadas, pode-se depreender que nos processos de educação formal o exercício de uma pedagogia comunicacional seja necessário, de modo que os professores, os alunos e os demais interlocutores na escola elaborem suas experiências levando em conta as experiências alheias.

Palavras-chave: Dewey, John - 1859-1952. Comunicação na Arte. Arte. Arte na Educação.

\section{Para citar este artigo:}

FONSECA, Cláudia Chaves; TOSTA, Sandra Pereira. Comunicação, arte e educação em John Dewey. Revista Linhas. Florianópolis, v. 20, n. 42, p. 238-254, jan./abr. 2019.

\section{DOI: 10.5965/1984723820422019238}

http://dx.doi.org/10.5965/1984723820422019238

\footnotetext{
${ }^{1}$ Este artigo é resultado de pesquisa que originou tese de doutorado financiada por bolsa da Capes.
}

\author{
Cláudia Chaves Fonseca \\ Pontifícia Universidade Católica \\ de Minas Gerais - PUC Minas - \\ Belo Horizonte/MG - Brasil \\ claufon@gmail.com \\ Sandra Pereira Tosta \\ Centro Universitário UNA - Belo \\ Horizonte/MG - Brasil \\ sandratostaeduc@gmail.com
}




\title{
Communication, Art and Education in the work of John Dewey
}

\begin{abstract}
This essay aims to analyze the articulation between the concepts of art and communication proposed by the North American educator John Dewey (1856-1952), in the book "Democracy and Education" (1916) and "Art as Experience" (1934), further inferring the developments of this reasoning on education. According to the author, communication is similar to art, as the participants need to develop empathy in both processes, through recognizing the existence of another and putting oneself in another's place. Since the author views communication and education as closely related, therefore it is necessary to adopt a communicational pedagogy in the process of formal education, in order that teachers, students and other actors in the school formulate their experience considering another's experience.
\end{abstract}

Keywords: Dewey, John - 1859-1952. Communication in the Art. Art. Art in Education. 


\section{Introdução}

Uma das grandes contribuições do educador norte-americano John Dewey (18591952) foi estabelecer uma perspectiva transdisciplinar ao pensamento educacional. Um dos maiores intelectuais de sua época, ele marcou lugar na História da Educação por ter sido um dos formuladores e um dos principais ideólogos do movimento de renovação educacional denominado Escola Progressista. O autor, em 96 anos de vida, deixou uma obra que recobre várias áreas do conhecimento, entre elas a Pedagogia, a Lógica, a Psicologia, a Estética e a Comunicação - esta última, uma disciplina acadêmica ainda em construção no final do século XIX e no início do XX.

Na obra mais importante de Dewey como filósofo educacional, Democracia e Educação, escrita em 1916, o autor define a comunicação como “processo de participação da experiência para que se torne patrimônio comum" (DEWEY, 1959b, p. 10) e propõe interessante homologia entre comunicação e arte, quando afirma que "toda comunicação é semelhante à arte" (DEWEY, 1959b, p. 6).

Dito isso, o objetivo deste artigo é refletir sobre os fundamentos dessa afirmativa por meio da interpretação de alguns conceitos, em particular o de experiência - alicerce do pensamento do autor - de modo a compreender quais seriam as características da relação entre comunicação e arte para Dewey, bem como reafirmar a importância dessa articulação de conceitos para a educação atual.

\section{Um autor ativista em favor da democracia}

É difícil classificar a obra de Dewey, pois sua curiosidade intelectual o levou a se interessar por um espectro de problemas que vão da Teoria do Conhecimento à Estética, passando pela Teoria do Currículo, os ditames da vida moral, o comportamento humano e a conceituação de liberdade na democracia. A diversidade de temas, porém, revela menos um ecletismo do que uma busca por pensar em conjunto diferentes aspectos da sociedade contemporânea, marcada pela acelerada transformação e mudança. Cunha (2001, p. 87), comentador de Dewey, afirma que a concepção de movimento "entendida como sinônimo de mundo em mudança" é signo distintivo do pensamento do autor e é sob essa perspectiva que sua obra deve ser compreendida. 
De fato, a vida de John Dewey transcorreu em um período da história norteamericana e mundial marcado pela alteração nos modos de vida material, nos valores e nas mentalidades. Certezas arraigadas foram abaladas ou desmoronaram por eventos como a Guerra de Secessão nos Estados Unidos (1861-1865), a Revolução Russa (1917) e as Guerras Mundiais (1914-1918 e 1939-1945).

Oriundo de família protestante episcopal, denominação que tem por tradição estimular a participação comunitária, o autor foi incentivado pela mãe a continuar os estudos em nível superior, graduando-se em 1879 em Filosofia. Seu engajamento nas discussões educacionais acontece a partir da última década do século XIX, quando é transferido para a Universidade de Chicago, nos Estados Unidos. O ambiente acadêmico vivenciado naquela instituição refletia o fenômeno urbano no qual estava inserida: Chicago era naquele tempo cidade-síntese do crescimento desordenado, fruto da migração interna de trabalhadores pobres, negros e brancos, para a indústria, além de receber imigrantes. Os problemas sociais de uma metrópole moderna destacavam-se nesse rol de questões concretas advindos da ordem capitalista que ora se consolidava. Tais conflitos desafiavam os intelectuais da academia, entre eles Dewey, o qual, a partir desta época, ligou-se à corrente filosófica do pragmatismo.

Baseado nos ideais pragmatistas, entre eles a recusa dos dualismos filosóficos, Dewey e sua esposa, a também professora, Alice Chapman, criaram em 1896 uma escola experimental na Universidade de Chicago, “propondo um modelo de educação pautado na cooperação e na resolução de problemas práticos” (MENDONÇA, 2013, p. 46). Esse foi um empreendimento institucional de fôlego, no qual se pôde animar e dar validade aos pressupostos filosóficos do grupo ao qual o casal era alinhado. Essa escola funcionou até 1904, enquanto contou com o apoio da universidade, sendo pioneira em vários sentidos, servindo de cenário para que fossem desenvolvidas propostas pedagógicas de renovação educacional. O autor centrava sua crítica à escola na qual o currículo e a tradição se impunham². Para Dewey, tal visão seria equivocada, entre outros fatores, por se aferrar à

\footnotetext{
${ }^{2}$ De acordo com Westbrook (2010), na década de 1880, um intenso debate ocorreu nos Estados Unidos entre os grupos tradicionalistas e reformistas da educação. Os primeiros advogavam o ensino baseado na tradição, no conhecimento acumulado organizado no programa (currículo). Os reformistas se opunham aos programas, defendendo que cada escola organizasse o conteúdo e a forma de ensinar. Dewey não concordava com ambos os grupos, sob o argumento de que a experiência dos alunos deveria ser levada para a sala de aula.
} 
ideia de preparação para a vida futura, valorizando a disciplina e a obediência em detrimento do raciocínio e da reflexão.

Dessa forma, a trajetória intelectual dewelyana foi marcada por uma produção de fôlego, com um acento engajado e ativista pela causa democrática, característica evidenciada em sua obra sobre educação. As temáticas de sua produção como pedagogo o fizeram conhecido no Brasil, especialmente pelas obras do educador baiano Anísio Teixeira (1900-1971) ${ }^{3}$. De acordo com Dewey, a educação não se aparta das demais dimensões da vida social e deve enfatizar os problemas do tempo presente.

\section{conceito de experiência}

Para Dewey, o pensamento racional que, entre outros frutos, proporcionou o desenvolvimento da ciência e seu desdobramento na tecnologia, trouxe também novos elementos para a compreensão da experiência humana. Nenhum aspecto da vida do homem moderno seria desvinculado das explicações científicas e das descobertas tecnológicas, uma vez que as máquinas, a luz elétrica e os meios de transporte estão presentes no cotidiano.

Os velhos modos de pensar, no entanto, de acordo com o autor, ainda seriam predominantes na Filosofia que oporia o indivíduo à sociedade, a teoria à prática, o interior ao exterior, entre outros dualismos. Na concepção de Dewey, a filosofia dualista, vigente no ocidente desde o século XVII, separava a mente do mundo, falhando por não dar lugar a posições intermediárias. A filosofia ocidental tenderia a formular generalidades, as quais eram colocadas como transcendentes à realidade concreta dos homens, afastando-se dos problemas concretos da vida social (DEWEY, 1959a).

Um dos idealizadores do pragmatismo filosófico norte-americano, ao lado de William James (1842-1910) e Charles Sanders Peirce (1839-1914), Dewey preconizou uma forma de pensar baseada no conceito de experiência. Segundo ele, a filosofia só poderia ser regenerada se as novas gerações fossem educadas em uma nova mentalidade, 0 raciocínio reflexivo, de modo a dissolver as demarcações rígidas entre conceitos tomados

\footnotetext{
${ }^{3}$ A respeito da influência deweyliana sobre os educadores brasileiros, consultar o artigo de Miriam Warde (2006).
} 
como opostos, tal como concebiam as principais correntes ocidentais do pensamento filosófico. O raciocínio reflexivo tem como ponto de partida a experiência, definida por Dewey como uma "força em movimento, resultado da interação entre uma criatura viva e algum aspecto do mundo em que ela vive" (DEWEY, 2011, p. 38).

O conceito de experiência modela as propostas educacionais de Dewey. O autor afirmou: "em uma sociedade democrática, o problema da educação é acabar com o dualismo e construir um plano de estudos que faça do pensamento um guia de prática livre, para todos (...)" (DEWEY, 1959b, p. 45-46). Segundo o autor, o pensamento é uma ferramenta que pode e deve ser usada na busca de soluções para os problemas cotidianos. Pensar não é uma habilidade oposta à vida prática ou separada dela, mas um exercício de mediação entre os construtos abstratos e o mundo, um levando ao outro.

Para Dewey, a sociedade moderna estaria diante de um desafio de extrema dificuldade, que é o de educar as novas gerações para viver na realidade complexa. Os membros mais jovens de uma sociedade precisam ser adaptados às exigências do mundo contemporâneo e, dadas às características da modernidade, somente a instrução e o exemplo familiar não são mais condições suficientes. Por isso a importância crescente da escola, "como um tipo de instituição social radicalmente distinta de qualquer outra forma de organização social". Dewey era um defensor da escola como lugar socialmente instituído de transmissão da vida social. No entanto, para ele, não há que se falar em transmissão: o papel da escola moderna seria o de reformular a experiência vivida pelos alunos, unindo a educação à vida, de modo que o educando fosse estimulado a dar conta dos desafios da situação presente e não ficasse à espera de um sucesso futuro.

O termo 'situação' tem conotação precisa para Dewey: são as condições objetivas em interação com as condições internas dos indivíduos. Lúcia Pimentel, em artigo em que discute as relações entre conhecimento e imaginação, afirma que para o autor:

(...) a construção de conhecimento ocorre com a participação ativa e interagente tanto do sujeito quanto dos outros corpos, sendo realizada em uma troca dialética que o sujeito realiza com a ambiência. Considerando a denominação ambiência para os aspectos do mundo onde a criatura viva está, tem-se que os elementos dessa ambiência, de uma forma ou outra, estão presentes constantemente, podendo ou não interagir entre si. (PIMENTEL, 2013, p. 97) 
A educação, assim, é concebida como processo de desenvolvimento e não como um fim a ser atingido ou um valor previamente determinado. O objetivo da escola seria 0 de proporcionar condições plenas para que o aluno possa se desenvolver continuamente, tomando como base a vivência trazida da vida familiar e social de forma a requalificá-la pelo raciocínio. Não se aprenderá na escola algo que seja apartado da vida social, mas nela se tomará os aspectos da vida social como iniciadores de um processo de reflexão que ampliará o conhecimento em extensão e em profundidade.

Dewey chama a isto de 'experiência educativa'. Uma experiência, para ser educativa, deve atender a dois princípios: o da continuidade e o da interação. Continuidade, para o autor, "significa que toda experiência tanto toma algo das experiências passadas quanto modifica de algum modo a qualidade das experiências que virão" (DEWEY, 2011, p. 36). Na sua argumentação, o processo educacional nunca é encerrado, quanto mais o ser humano encontra significado no que aprende, mais busca aprender.

O segundo princípio é o da interação ou comunicação, isto é, a experiência, para ser considerada educativa, deve ser comunicada, deve ser revestida de caráter público. A possibilidade de compartilhamento, ensejado por um ambiente em que a expressão seja valorizada, engrandece a experiência, reafirma a dimensão social da educação e modifica, de algum modo, a experiência dos interlocutores. Para Dewey, a continuidade e a interação dão a medida de valor a uma experiência e a principal tarefa da escola seria a de formar "o desejo de continuar aprendendo" (DEWEY, 2011, p. 50).

\section{O papel da comunicação na reconstrução da experiência}

O termo comunicação, em sua acepção contemporânea, é recente. Remonta ao século XIX a utilização de uma só palavra para nomear e descrever esse extenso leque de atividades humanas, como entabular uma conversa, fazer um gesto, escrever uma carta, redigir uma matéria jornalística, etc. A comunicação, como um termo 'guarda-chuva', nem sempre encontra um significado preciso, apontando para ideias como troca, conversa, diálogo, produção e transmissão de informação, entre outras. É relevante salientar - e 
certamente não foi coincidência - que a unificação do termo tenha acontecido ao mesmo tempo em que os modos de interação na sociedade adquiriram feição coletiva.

Nos Estados Unidos, país em que a invenção e a disseminação dos meios de comunicação se fez sentir intensamente na vida cotidiana e em relação ao qual se pode dizer, com alguma certeza, que foi o lugar em que uma 'indústria da cultura' inicialmente floresceu com vigor, o termo comunicação apareceu no século XIX. Embora não tenha sido um teórico da comunicação, John Dewey foi "um dos primeiros pesquisadores americanos a falar explicitamente neste vocábulo", como afirma Varão (2014, p. 131). O emprego do termo pelo autor influenciou, inclusive, os estudiosos que estruturariam a nascente disciplina Teoria da Comunicação, entre eles o sociólogo e cientista político Harold Laswell (1902-1978), pioneiro nas análises sobre a comunicação coletiva.

Dewey foi amadurecendo, ao longo dos escritos, sua própria acepção de comunicação, na medida em que o conceito de experiência, como já foi dito, também é refinado. De simples troca, decalcada de processos fisiológicos, a reflexão sobre o termo "comunicação" vai evoluindo até se transformar propriamente em um conceito, com força suficiente para sustentar os argumentos que se encontram de forma plena no livro The Public and its problems (1927) 4 . Em 1916, por exemplo, quando publica Democracia e Educação, obra mais importante do autor no campo educacional, já no primeiro capítulo a comunicação é mencionada. É por meio da comunicação, segundo Dewey, que se efetua a transmissão da vida social a qual, nas sociedades humanas, não se faz apenas por imperativos biológicos, mas também - e principalmente - pela renovação dos "hábitos de proceder, pensar e sentir" (DEWEY, 1959b, p. 3).

Nesse ponto, já se percebe a abordagem cultural que Dewey faz da comunicação. Comunicar-se, para ele, é agir em prol do estabelecimento de um espaço simbólico comum, em direção a uma finalidade comum. É uma troca simbólica que reconstrói o mundo percebido pelos interlocutores. A comunicação seria genuína quando, por meio dela, a experiência dos interlocutores se ampliasse em um processo que requer participação e cumplicidade. Esse ponto de vista é defendido pelo autor ao argumentar que:

\footnotetext{
${ }^{4}$ O público e seus problemas, livro não traduzido em Português.
} 
Tentai comunicar plena e cuidadosamente a outra pessoa vossa experiência pessoal, principalmente em se tratando de algo complicado, que notareis mudar-se vossa própria atitude para com a referida experiência: a não ser que tenhais recorrido a mera verbiagem bombástica. É mister, com efeito, que se formule a experiência para que seja comunicada. (DEWEY, 1959b, p. 6)

A noção de interlocução é fundamental na medida em que os participantes do processo comunicacional dispõem-se diante uns dos outros, organizando o pensamento e, num processo que exige empatia, compartilham ideias, sentimentos, emoções, etc. As diferentes modalidades de linguagem - instrumentos comunicacionais - são orientadas para o interlocutor e são de natureza social. O ato comunicativo é tão prenhe de possibilidades que o autor chegou a compará-lo a um "prodígio" (DEWEY, 1985).

Na referência aos processos comunicacionais, Dewey não se resume ao papel dos meios de comunicação coletiva, mas, principalmente, aos processos interpessoais e grupais. A relação professor-aluno durante a aula, por exemplo, é eminentemente comunicativa e tem que ser compreendida nesses termos. Além disso, não é todo tipo de comunicação que serve à escola, instituição que tem por finalidade propiciar experiências educativas.

O autor indica a contradição existente em nossa sociedade, que construiu todo um aparato dito comunicativo, mas cuja lógica de funcionamento traz como consequência prática um enfraquecimento do espírito crítico. Os meios de comunicação se constituem em um aparato comercial que pode se tornar obstáculo à formação da opinião pública democrática e, por conseguinte, formar entraves ou até mesmo impedir as experiências educativas.

Ao dissertar sobre o conceito de liberdade, Dewey o entende como "mais uma atitude mental do que a ausência de restrição exterior de movimentos" (DEWEY, 1959b, p. 337) e formulou em diversas passagens um alerta sobre os perigos das tecnologias de comunicação na alteração das condições culturais. Segundo ele, não somente o excesso, mas também a desconexão das informações desorienta o indivíduo e o desabilita a formar opinião: 
(...) outros poderosos fatores atuantes são aquelas tecnologias produzidas pela ciência moderna, que multiplicaram os meios de modificar as disposições da massa da população, e que, conjugadas com a centralização econômica, habilitaram a produção em massa, como a de quaisquer outros bens físicos, da opinião pública. Aí também temos, ao mesmo tempo, uma advertência e uma sugestão aos que estão preocupados com as condições culturais capazes de manter a liberdade democrática. A advertência é óbvia quanto ao papel da propaganda, que opera agora conosco em canais menos diretos e oficiais. A sugestão é a de que a imprensa e o rádio tornaram o problema do uso inteligente e honesto dos meios de comunicação, para fins abertamente públicos, matéria de profunda preocupação. (DEWEY, 1970, p. 130)

O autor afirma que os meios de comunicação coletiva, justamente por colocarem à disposição dos indivíduos uma quantidade enorme de informação, acabam por usar estratégias de excitação emocional ('verbiagem bombástica') para conseguir atenção. Para o autor, os meios de comunicação coletiva geram uma grande tensão, pois oscilam entre favorecer a comunicação e promover a incomunicação.

\section{A experiência artística}

Segundo Dewey, nenhuma experiência é puramente intelectual ou emocional. Para ser genuína, ou seja, para garantir a continuidade e a interação, a experiência deve integrar as várias dimensões da vida humana, conferindo uma sensação de unidade. Por isso, a experiência autêntica tem uma qualidade estética, ela é consumatória, deixa em seu espírito uma impressão viva e o envolve plenamente. No livro $A$ arte como experiência (1985), Dewey reflete sobre o caráter simultaneamente intelectual e emocional das experiências:

Uma experiência possui uma unidade que lhe confere seu nome, aquela comida, aquela tempestade, aquela ruptura de amizade. A existência dessa unidade está constituída por uma qualidade única que penetra toda a experiência, apesar da diferença de suas partes consecutivas. Unidade que não é emocional, nem prática, nem intelectual, porque esses termos denominam distinções que a reflexão pode estabelecer no interior dela. (DEWEY, 1985, p. 90) 
O que confere unidade - ou significado pleno - a uma experiência é sua qualidade estética. Qualidade estética é a capacidade de operar uma transformação a partir da interação com os elementos prévios, é mudar de patamar em propósito e direção, de forma que haja uma autêntica mudança. A essa qualidade rara, o autor denomina como “drama ou ficção”, que talvez possa ser compreendida como a possibilidade humana de ir além das circunstâncias dadas, a capacidade de favorecer o que não estava previsto, criando uma nova ordenação e imprimindo uma nova cor ao vivido.

É importante lembrar que 'qualidade estética da experiência' não é o mesmo que 'qualidade da experiência estética', ainda que ambas estejam associadas. A arte é um tipo particular de experiência, que se caracteriza pela capacidade de 'pensar relacionalmente as qualidades'. A obra artística tanto é um produto, quanto o próprio processo de execução, de modo que o artista simultanemante 'faz e padece' a própria obra.

A criação artística, de acordo com Dewey, é um processo empático, pois o artista se coloca no lugar do apreciador, precisa simultaneamente produzir e antecipar a recepção:

O homem talha, esculpe, canta, dança, gesticula, modela, desenha e pinta. O fazer ou obrar é artístico quando o resultado percebido é de tal natureza que suas qualidades enquanto percebidas controlaram a produção. $O$ ato de produzir dirigido pela intenção de produzir alguma coisa gozada na experiência imediata do perceber tem qualidades que uma atividade espontânea ou não controlada não tem. O artista incorpora a si próprio a atitude do que percebe, enquanto trabalha. (DEWEY, 1985, p. 99)

A experiência estética requer, portanto, imaginação, tanto daquilo que será concebido quanto da percepção de outrem. O artista cria e percebe sua obra:

um artista, em comparação com seus próximos, é alguém que não apenas é especialmente dotado com poderes de execução, mas também com sensibilidade incomum para as qualidades das coisas. Tal sensibilidade dirige também seu fazer e seu obrar. (DEWEY, 1985, p. 100)

Ao refletir sobre a experiência estética, provavelmente Dewey quis exemplificar como se pode pensar de modo não dualístico. Essa visão pode ser encontrada no artigo 
Cultura e Indústria na Educação. ${ }^{5}$ Tomando a arte como tema, refuta as tentações de analisá-la por meio de oposições como artista e público, criação e fruição, entre outras, demonstrando que qualquer atividade humana - inclusive a arte - é um contínuo de criação e recriação. O artista controla, até certo ponto, o fazer e o refazer de sua criação. Uma obra somente é considerada artística se entrar em um fluxo interacional no qual determinadas qualidades são valorizadas como tal e compartilhadas.

\section{Comunicação e Arte}

Ao apresentar a educação como necessidade da vida social, imperativa nas complexas sociedades modernas, Dewey afirma, no primeiro capítulo de Democracia e Educação, que a vida social não persistiria se não houvesse comunicação entre seus membros, uma vez que a mera continuidade biológica não garante a sociabilidade. No desenvolvimento da argumentação, ao longo do texto, o autor esmiúça o termo, demonstrando a conexão entre educação e comunicação. Na parte 2, afirma que "toda a comunicação é semelhante à arte" (DEWEY, 1959b, p. 6). Quais seriam, pois, os fundamentos que levaram o autor a fazer essa afirmação? Quais características o autor percebeu em ambas as atividades humanas que o levaram a reconhecer a semelhança, propondo essa homologia?

Levando-se em consideração a noção de experiência, o autor afirma que arte e comunicação não se reduzem uma à outra, não são exatamente a mesma coisa, mas se assemelham. A partir de quais elementos o fez? É possível fazer, com base nas proposições de Dewey, um exercício de interpretação, buscando as seguintes aproximações: i) o comunicador e o artista movem-se pela imaginação e pela empatia; ii) a comunicação e a arte abrangem tanto o resultado daquilo que é feito quanto o processo de execução; iii) comunicação e arte são atividades sujeitas a elementos imponderáveis, pois nelas há um elemento de paixão.

Mover-se pela imaginação significa que tanto o comunicador quanto o artista precisam ter uma atitude empática: colocar-se no lugar do outro, antecipar-se às reações e redirecionar o sentido. A busca da intersubjetividade exercida por meio de um material

\footnotetext{
${ }^{5}$ Reproduzido no livro de Ana Mae Barbosa, John Dewey e o ensino de arte no Brasil (2002).
} 
simbólico é característica tanto da arte como da comunicação. O resultado pretendido de uma comunicação ou de uma obra de arte leva em consideração aquilo que um 'outro' perceberia sobre a matéria. Quem escreve uma carta, por exemplo, imagina uma resposta, escolhendo as palavras de acordo com o efeito que espera causar; também o pintor volta a trabalhar em um quadro após distanciar-se dele para tentar vê-lo como apreciador. Mesmo quando a comunicação é exercitada de forma estratégica e/ou mercadológica - como é o caso da comunicação coletiva - uma alteridade é pressuposta, ainda que a finalidade seja persuadir.

Da mesma forma, quando nos comunicamos ou executamos uma obra de arte, o resultado pretendido não é realmente o ponto final, não existe propriamente um produto pronto e acabado. Um processo se desenrola, um diálogo pode dar lugar a outro, um texto gera novos textos, uma pintura gera inúmeras apreciações. A relação que se estabelece entre as subjetividades é tão ou mais relevante que a finalidade a alcançar, até mesmo porque tal relação é da ordem do imponderável, pode escapar dos cálculos e dos planejamentos.

De acordo com Dewey, ao dissertar sobre a arte, a 'obra' é a materialização de um trabalho prévio, que já ocorreu na mente do artista: seria a “incorporação externa” de um impulso que, por este ato, se torna social, deixando de ser apenas um delírio. Explica o autor:

Não é por qualquer acidente linguístico que 'edificação', 'construção' e 'obra' designam tanto um processo quanto seu produto acabado. Sem o significado do verbo, permanece vazio o do substantivo. (DEWEY, 1985, p. 101)

A comunicação e a arte são, portanto, processos constituídos por fases que se influenciam mutuamente. Sobre esse aspecto, explica França (2007, p. 4): “não se trata aqui de uma relação causal, mas de uma dinâmica circular, de um movimento de reflexividade". As fases que constituem os processos são conscientes e significativas, pois o ser humano é um animal que interage por meio dos símbolos, e não das próprias coisas. Nem tudo aquilo que é comunicado ou criado é significativo, somente o será se houver compartilhamento de um mundo comum, permeado pela linguagem. 
Nos processos comunicativos e artísticos, tanto o indivíduo como a sociedade se revelam e se afetam. O artista cria, mas sua criação é percebida como arte em um meio social em que aquele artefato seja reconhecido como tal. Isso não quer dizer que o artista não possa forçar os limites - e frequentemente o faz, uma vez que a arte busca explorar as fronteiras dos sentidos - porém, esses limites avançam por meio de novos acordos sociais.

A imponderabilidade presente nas relações comunicacionais e artísticas é o terceiro pressuposto. Qualquer atividade humana está sujeita ao inesperado, mas nesses dois campos, particularmente, o imponderável é bem-vindo como motor e como catalisador da ação. O imponderável reconduz a ação para novos caminhos. Dewey se refere ao ‘elemento de paixão’ que existe na percepção estética para descrever a emoção como referencial intrínseco a qualquer ato artístico. A inquietação, a perplexidade, a surpresa levam ao ato de criação. Ele pondera, no entanto, que a paixão (ou as emoções) são importantes como impulso, mas durante a execução o ímpeto deve ser domado em prol do propósito almejado. A arte possui dois elementos: um de ação e outro de reação, cuja ligação é a sensibilidade: “o feito e o sofrido são, portanto, recíproca, cumulativa e continuamente instrumental um com respeito ao outro" (DEWEY, 1985, p. 100). Se assim não fosse, ressalva o autor, o artista criaria de forma mecânica ou então devanearia, e a comunicação se tornaria um monólogo.

Dewey considera, sobretudo, que tanto arte como comunicação se assemelham porque são sustentadas nas relações sociais. Andrade e Cunha, a este respeito, afirmam que:

Em Arte como experiência, Dewey (2010a, p. 126) define arte como experiência e como forma de linguagem, a situando no âmbito das práticas sociais. Assim, o autor contraria frontalmente a definição hegemonicamente aceita que atribui ao fazer artístico uma condição superior, um caráter perfectivo isolado das condições concretas de criação, uma prática que emana de instâncias metafísicas, realizada somente por quem possui um dom que o aproxima da esfera divina. (FERNANDES DE ANDRADE; CUNHA, 2016, p. 308)

São expressões do espírito humano que ganham vida por meio de ações, decorrentes de necessidades práticas. Essas ações, por seu turno, emaranham-se numa 
torrente de interações linguísticas de todo tipo, evocando significados. É importante observar que ambos os domínios são analisados pelo autor como experiências: ele não pretendeu, por exemplo, analisar a influência do mercado sobre a comunicação e a arte.

Arte e comunicação se aproximam porque são, ao mesmo tempo, experiências com dimensões instrumentais e consumatórias: possuem finalidades, produzem "coisas" e suscitam efeitos, mas, no movimento mesmo de fazê-lo, envolvem os interlocutores por inteiro, abrem um leque de escolhas, ampliam as possibilidades da inteligência humana em todas as dimensões da experiência.

\section{A educação como processo comunicativo}

A sociedade, para Dewey, se constitui tanto em uma dimensão vertical, na qual as gerações mais velhas transmitem seu legado cultural para os jovens, como por uma dimensão horizontal, que é a da comunicação. Ambas são inseparáveis, pois uma sociedade é formada por um "modo comum de compreender". A comunicação, para o autor, tanto é a interação para a consecução de uma finalidade, como também - e principalmente - a compreensão dessa finalidade, a coparticipação para a realização comum dos interesses. Por isso, para ele, "toda a vida social é comunicativa" (DEWEY, 1959b, p. 5). Para o autor, a comunicação é caracterizada pela construção e pelo reconhecimento de elementos comuns, ainda que as partes envolvidas abram mão de algum interesse ou acreditem ser mais vantajosa a formação do consenso.

A escola é um lugar de interações comunicativas por excelência. A educação formal, para ser efetivada, requer de todos os seus participantes o desenvolvimento de habilidades comunicacionais. Não é qualquer forma de comunicação, no entanto, que serve à escola. Na concepção de Dewey, a mera transferência de conteúdos não pode ser considerada como educativa, porque não é comunicativa, ou seja, a transmissão não é capaz de ensejar a construção de um mundo comum.

De acordo com Cunha: 
Em Democracia e Educação, Dewey (1959b, p. 207) considera fundamental que o conhecimento seja ensinado sempre em estreita conexão com a experiência do educando. "Nada se objeta - diz o autor - a que as informações sejam expressas com palavras; a comunicação opera-se necessariamente por meio de palavras". Mas se o conteúdo comunicado não estiver "incorporado à experiência existente de quem aprende", a comunicação "converte-se em simples palavras, isto é, em puros estímulos sensoriais, desprovidos de significação". (CUNHA, 2005, p. 9)

Nessa perspectiva, Dewey considera o professor como aquele que constrói narrativas em sala de aula. Ele elabora sua experiência com a matéria e auxilia os alunos a formularem e a submeterem à prova suas próprias experiências, construindo uma narrativa que não é mais informal. Assim, o autor coloca em movimento uma pedagogia da comunicação. A pedagogia comunicativa é viva e assemelha-se à arte: a mensagem educativa é elaborada em um processo empático, horizontal.

A comunicação na escola não deve ser rotineira. Sobre isso, conclui Dewey: "toda a prática social que seja vitalmente social ou vitalmente compartilhada é por sua natureza educativa. Só quando lançada em um molde e tornada rotineira é que perde seu valor educativo" (DEWEY, 1959b, p. 6). A verticalidade em sala de aula transforma a autoridade do professor em autoritarismo, causando obstáculo à comunicação, que dessa forma perde seu potencial de transformação e seu sentido estético.

\section{Referências}

BARBOSA, Ana Mae. John Dewey e o ensino da arte no Brasil. $5^{\text {a }}$. ed. São Paulo: Cortez, 2002.

CUNHA, Marcus Vinícius. John Dewey e o pensamento educacional brasileiro: a centralidade da noção de movimento. Revista Brasileira de Educação, São Paulo, n. 17, maio/ago., 2001.

CUNHA, Marcus Vinícius. Comunicação e arte, ou a arte da comunicação, em John Dewey. R. Bras. Est. Pedag., Brasília, v. 86, n. 213/214, p. 9-20, maio/dez. 2005.

DEWEY, John. Democracia e educação. São Paulo: Cia. Editora Nacional, 1959a.

DEWEY, John. Reconstrução em filosofia. $2^{\text {a }}$ ed. São Paulo: Cia. Editora Nacional, 1959b. 
DEWEY, John. A Arte como experiência. $2^{\text {a }}$. ed. São Paulo: Abril Cultural, 1985. (Col. Os Pensadores)

DEWEY, John. Experiência e educação. 2ª . ed. Petrópolis: Vozes, 2011.

DEWEY, John. Liberalismo, liberdade e cultura. São Paulo: ed. Nacional/USP, 1970.

FERNANDES DE ANDRADE, Erika; CUNHA, Marcus Vinícius. A contribuição de John Dewey ao ensino da arte no Brasil. Espacio, Tiempo y Educación, Salamanca, v. 3, n. 2, p. 301-319, 2016.

FRANÇA, Vera. Contribuições de G.H. Mead para pensar a comunicação. In: ENCONTRO DA COMPOS, XVI, Curitiba, 2007. Anais [...]. Curitiba: editor, 2007.

MENDONÇA, Ricardo Fabrino. A liberdade de expressão em uma chave não dualista: as contribuições de John Dewey. In: GUIMARÃES, Juarez; AMORIM, Ana Paola (Org.) A corrupção na opinião pública: uma defesa republicana da liberdade de expressão. São Paulo: Boitempo: 2013.

PIMENTEL, Lúcia. Cognição Imaginativa. Pós: Revista do Programa de Pós-Graduação em Belas Artes, Belo Horizonte, v. 3, n. 6, nov. 2013.

VARÃO, Rafiza; CUNHA, Raquel Cantarelli. O conceito de comunicação em John Dewey: de 1884 a 1927. Comunicologia, Brasília, s/n, 2014.

WARDE, Miriam J. Encantamentos e desencantamentos com a América: os Estados Unidos em escritas de Anísio Teixeira. Proj. História, São Paulo, v. 32, p. 171-189, jun. 2006.

WESTBROOK, Robert. John Dewey Recife/PE: Fundação Joaquim Nabuco; Ed. Massagana, 2010. (Col. Educadores MEC). 